\title{
CDDITA-Based Voltage-Mode First Order All Pass Filter Configuration
}

\author{
Dinesh Prasad ${ }^{*}$, Kuldeep Panwar², D. R. Bhaskar1, Mayank Srivastava ${ }^{3}$ \\ ${ }^{1}$ Department of Electronics and Communication Engineering, Faculty of Engineering and Technology, \\ Jamia Millia Islamia, New Delhi, India \\ ${ }^{2}$ Department of Electronics and Communication, HMRITM, Delhi, India \\ ${ }^{3}$ Department of Electronics and Communication Engineering, Amity University Uttar Pradesh, Noida, India \\ Email: *dprasad@jmi.ac.in, kuldeeppanwar.dce@gmail.com,dbhaskar@jmi.ac.in, mayank2780@gmail.com
}

Received 14 October 2015; accepted 15 November 2015; published 18 November 2015

Copyright (C) 2015 by authors and Scientific Research Publishing Inc.

This work is licensed under the Creative Commons Attribution International License (CC BY).

http://creativecommons.org/licenses/by/4.0/

(c) (i) Open Access

\section{Abstract}

This realization of a voltage-mode first order voltage-mode all pass filter (VM-APF) employing single current differencing differential input transconductance amplifier (CDDITA) as active component is presented. The proposed configuration employs one CDDITA along with two resistors and one grounded capacitor. The pole frequency and phase shift of proposed VM-APF are electronically tunable by transconductance of CDDITA. The proposed circuit is verified by SPICE simulations.

\section{Keywords}

CDDITA, All Pass Filter, First Order

\section{Introduction}

An first order all-pass filter is one of the most important building block of many analog signal generation/processing applications. It is frequently used for phase shifting purpose while maintaining the amplitude of signal constant over the desired range of frequency. It finds applications in realizing high selectivity active bandpass filters, delay equalizers and quadrature oscillators [1] [2]. Several voltage mode voltage-mode first-order allpass filter configurations employing different active building blocks (ABBs) such as, current conveyors (CCIIs) [3]-[9], Operational Transconductance Amplifiers (OTAs) [10] [11], current controlled current conveyors (CCCIIs) [12]-[14], differential voltage current conveyor (DVCC) [15]-[17], differential difference current conveyors (DDCCs) [18]-[20], current differencing buffered amplifier (CDBA) [21]-[23], operational transresis-

\footnotetext{
${ }^{*}$ Corresponding author.
} 
tance amplifiers (OTRAs) [24]-[26], current controlled current differencing transconductance amplifiers (CCCDTA) [27], universal voltage conveyor [28] and Fully Balanced Voltage Differencing Buffered Amplifier (FBVDBA) [29] have been reported in literature but unfortunately, these proposed configurations suffer from one or more of the following drawbacks: i) use of excessive (more than one) number of ABBs [6] [8] [10] [11] [12] [14]; ii) use of excessive (more than two) number of resistors [3] [7] [20] [22] [23] [26]; iii) use of excessive (more than one) number of capacitors [4] [5] [8] [12] [15] [23]; iv) use of floating capacitors [9] [11]-[14] [18] [22]-[25] [27] [28] and v) Non availability of electronic control [3]-[9] [15]-[20] [23]-[26] [28] [29].

Therefore, the aim of this paper is to propose a new voltage-mode all-pass with following advantageous features: i) Single ABB realization; ii) use of only two resistors; iii) use of only one capacitor; iv) use of grounded capacitor which is desirable from the viewpoint of monolithic integration and v) electronically tunable phase and pole frequency.

\section{The Proposed New Configuration}

The CDDITA is one of the recent active ABB which have been introduced in [30]. Figure 1 shows the symbolic representation of CDDITA, where $\mathrm{P}$ and $\mathrm{N}$ are input ports, $\mathrm{z}$ is auxiliary port, $\mathrm{X}+$ and $\mathrm{X}$ - are output ports and $\mathrm{V}$ is buffered port with all ports at high impedance level except $\mathrm{P}$ and $\mathrm{N}$ which are low impedance ports. The behavioural model of CDDITA given in Figure 2, shows that a CDDITA consist of a current differencing unit (CDU) followed by an operational transconductance amplifier. The CMOS implementation of CDDITA has been shown in Figure 3 [31].

The proposed voltage-mode first order all-pass filter (VM-APF) is shown in Figure 4.

The routine circuit analysis of proposed VM-APS shown in Figure 4, yields the following voltage mode transfer function

$$
\frac{V_{0}(s)}{V_{i n}(s)}=\frac{\left(s C-g_{m}\right)}{\left(s C+g_{m}\right)}
$$

for

$$
\frac{1}{R_{1}}=\frac{1}{R_{2}}=g_{m}
$$

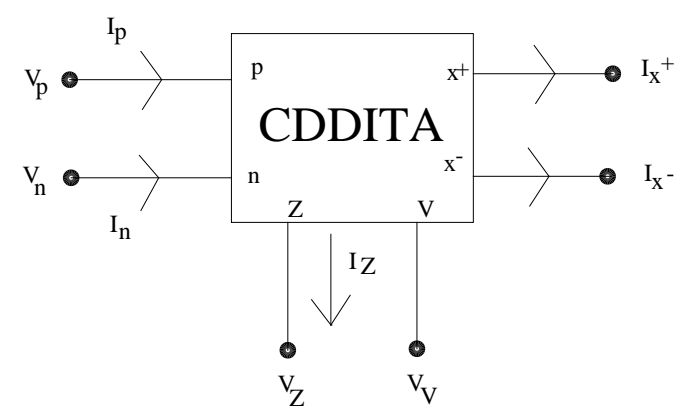

Figure 1. CDDITA symbolic representation.

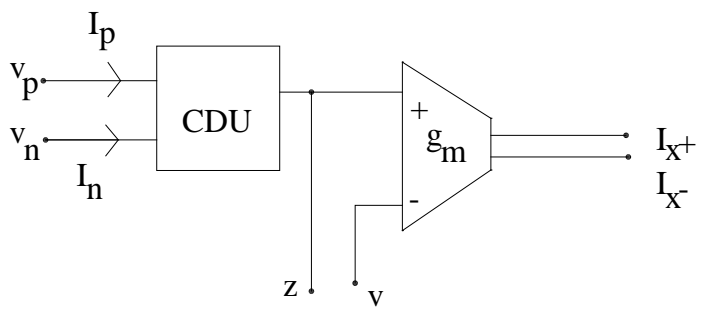

Figure 2. Behavioural model of CDDITA. 


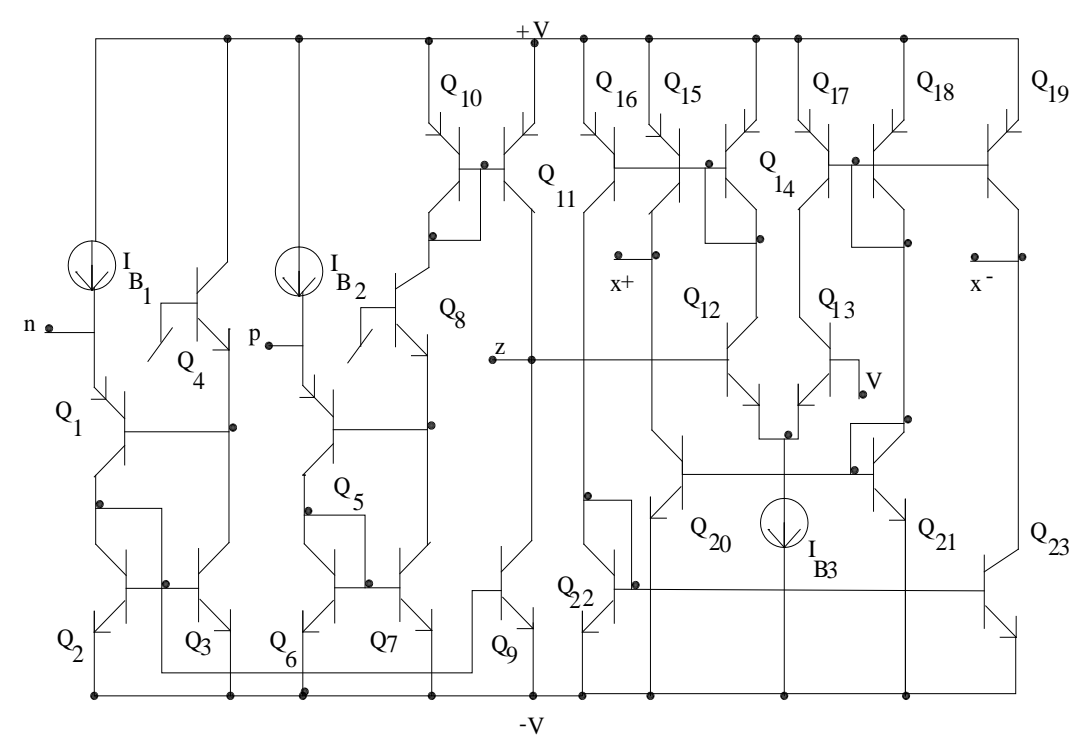

Figure 3. CMOS implementation of CDDITA [31].

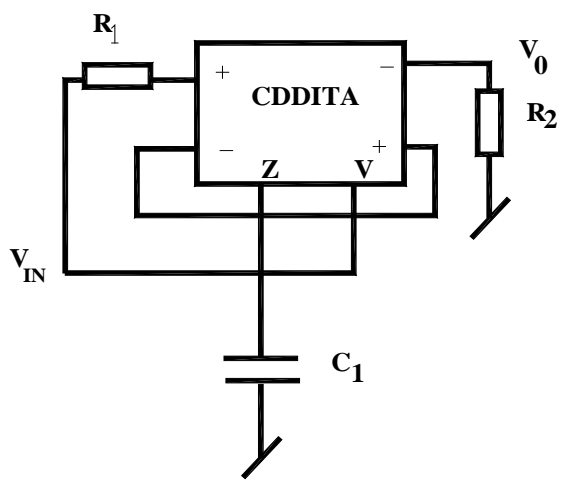

\section{Figure 4. Proposed VM-APF.}

From Equation (1) it is clear that voltage gain is unity. The pole frequency and phase response obtained from Equation (1) are

$$
\omega_{0}=\frac{g_{m}}{C}
$$

and

$$
\angle \frac{V_{0}(s)}{V_{\text {in }}(s)}=\phi\left(\omega_{p}\right)=\pi-2 \tan ^{-1}\left(\frac{\omega_{p} C}{g_{m}}\right)
$$

So, proposed circuit provides phase shift from 0 to $180^{\circ}$. The pole frequency is electronically tunable by transconductance $g_{m}$.

\section{Simulation Results}

The circuit illustrated in Figure 4 is tested by SPICE simulations (OrCAD 9.1 Version). The simulations were performed employing Bipolar-based CDDITA (shown in Figure 3 ) with supply voltages $\pm 3 \mathrm{~V}$ DC, with biasing currents $I B_{1}=I B_{2}=I B_{3}=100 \mu \mathrm{A}$ and with the transistor model parameters of PR100 N(PNP) and NR100 $\mathrm{N}(\mathrm{NPN})$ of the bipolar arrays ALA400 from AT\&T [32]. The component values used were $C=100 \mathrm{nF}, R_{1}=R_{2}$ $=500 \Omega$. The frequency and phase responses of proposed VM-APF are shown in Figure 5 . 


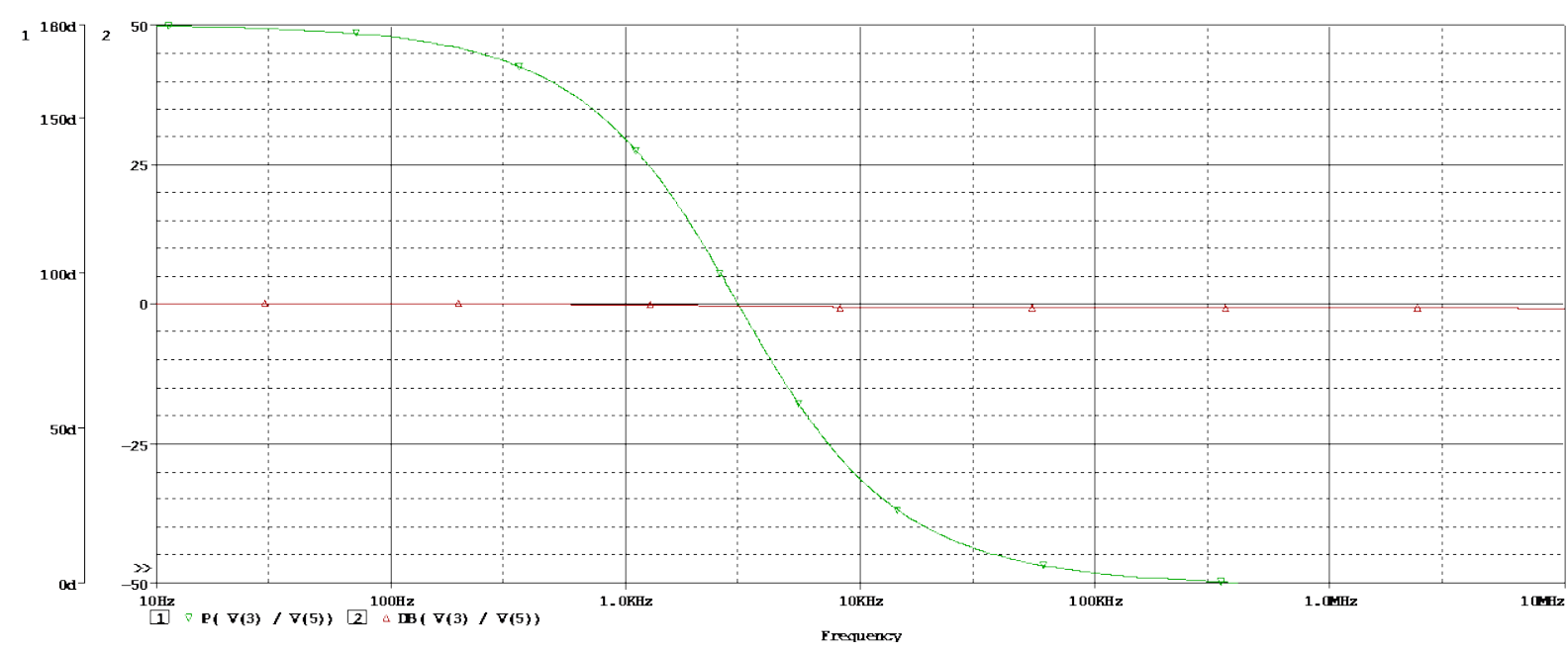

Figure 5. Frequency and phase responses of proposed VM-APF.

\section{Conclusion}

A new voltage-mode first-order all-pass filter employing single CDDITA, two resistors and one grounded capacitor is presented. The positive features of proposed circuit are use of single ABB, use of grounded capacitor and availability of electronic tuning feature. The theoretical analysis is verified by SPICE simulations.

\section{References}

[1] Schauman, R. and Valkenburg, E. (2001) Design of Analog Filters. Oxford University Press, New York.

[2] Donald, T.C., David, T.C. and Jason, R.G. (1997) A High Frequency Integrable Band-Pass Filter Configuration. IEEE Transactions on Circuits and Systems, 44, 856-860. http://dx.doi.org/10.1109/82.633445

[3] Cicekoglu, O., Kuntman, H. and Berk, S. (1999) All-Pass Filters Using a Single Current Conveyor. International Journal of Electronics, 86, 947-959. http://dx.doi.org/10.1080/002072199132941

[4] Higashimura, M. and Fukai, Y. (1988) Realization of All-Pass and Notch Filters Using a Single Current Conveyor. International Journal of Electronics, 65, 823-828. http://dx.doi.org/10.1080/00207218808945282

[5] Cicekoglu, O. and Kuntman, H.H. (1998) CCII+ Based First Order All Pass Filters with All Grounded Passive Elements. Proceeding of MELECON, 1, 608-612.

[6] Pal, K. and Rana, S. (2004) Some New First-Order All-Pass Realizations Using CCII. Active and Passive Electronic Components, 27, 91-94. http://dx.doi.org/10.1080/0882751031000116188

[7] Soliman, M. (1997) Generation of Current Conveyor-Based All-Pass Filters from Op Amp-Based Circuits. IEEE Transactions on Circuits and Systems-II, 44, 324-330. http://dx.doi.org/10.1109/82.566650

[8] Horng, J.W. (2005) Current Conveyors Based All Pass Filters and Quadrature Oscillators Employing Grounded Capacitors and Resistors. Computers \& Electrical Engineering, 31, 81-92.

http://dx.doi.org/10.1016/j.compeleceng.2004.11.006

[9] Ibrahim, M.A., Kuntman, H., Ozcan, S., Suvak, O. and Cicekoglu, O. (2004) New First-Order Inverting-Type SecondGeneration Current Conveyor-Based All-Pass Sections Including Canonical Forms. Electrical Engineering, 86, 299301. http://dx.doi.org/10.1007/s00202-003-0205-3

[10] Keskin, A.U., Pal, K. and Hanciogluc, E. (2008) Resistorless First Order All-Pass Filter with Electronic Tuning. International Journal of Electronics and Communications (AEU), 62, 304-306. http://dx.doi.org/10.1016/j.aeue.2007.04.001

[11] Kumngern, M. and Chanwutitum, J. (2012) Voltage-Mode First-Order Allpass Filter Using Single-Ended OTAs and Grounded Capacitor. 2012 2nd International Conference on Digital Information and Communication Technology and It's Applications (DICTAP), Bangkok, 16-18 May 2012, 305-308. http://ieeexplore.ieee.org/xpl/abstractKeywords.jsp?reload=true\&arnumber=6215363

[12] Kumar, P., Keskin, A.U. and Pal, K. (2007) Wide-Band Resistorless All-Pass Sections with Single Element Tuning. International Journal of Electronics, 94, 597-604. http://dx.doi.org/10.1080/00207210701289676

[13] Toker, A., Gune, E.O. and Ozoguz, S. (2001) New High-Q Band-Pass Filter Configuration Using Current Controlled 
Current Conveyor Based All-Pass Filters. Proceeding of ICECS, 1, 165-168. http://dx.doi.org/10.1109/icecs.2001.957706

[14] Minaei, S. and Cicekoglu, O. (2006) A Resistorless Realization of the First-Order All-Pass Filter. International Journal of Electronics, 93, 177-183. http://dx.doi.org/10.1080/00207210600562173

[15] Ibrahim, M.A., Minaei, S. and Kuntman, H. (2006) A DVCC Based Differential-Mode All-Pass and Notch Filters with High CMRR. International Journal of Electronics, 93, 231-240. http://dx.doi.org/10.1080/00207210600562181

[16] Horng, J.W. (2009) High Input Impedance First-Order Allpass, Highpass and Lowpass Filters with Grounded Capacitor Using Single DVCC. Indian Journal of Engineering \& Materials Sciences, 17, 175-178.

[17] Chen, H.P., Huang, K.W. and Huang, P.M. (2012) DVCC-Based First-Order Filter with Grounded Capacitor. International Journal of Information and Electronics Engineering, 2, 50-54. http://dx.doi.org/10.7763/ijiee.2012.v2.54

[18] Ibrahim, M.A., Kuntman, H. and Cicekoglu, O. (2003) First-Order All Pass Filter Canonical in the Number of Resistors and Capacitors Employing a Single DDCC. Circuits, Systems, and Signal Processing, 22, 525-536. http://dx.doi.org/10.1007/s00034-003-1111-7

[19] Horng, J.W., Hou, C.-L., Chang, C.-M., Lin, Y.-T., Shiu, I.-C. and Chiu, W.-Y. (2006) First-Order All-Pass Filter and Sinusoidal Oscillators Using DDCCs. International Journal of Electronics, 93, 457-466. http://dx.doi.org/10.1080/00207210600711481

[20] Horng, J.W., Wu, C.M. and Herencsar, N. (2014) Fully Differential First-Order Allpass Filters Using a DDCC. Indian Journal of Engineering \& Materials Sciences, 21, 345-350.

[21] Toker, A., Ozoguz, S., Cicekoglu, O. and Acar, C. (2000) Current Mode Allpass Filters Using Current Differencing Buffered Amplifier and New High-Q Band-Pass Filter Configuration. IEEE Transaction on Circuits and Systems-II, 47, 949-954. http://dx.doi.org/10.1109/82.868465

[22] Maheshwari, S. (2006) Voltage-Mode All-Pass Filters Including Minimum Component Count Circuits. Active and Passive Electronic Components, 2007, Article ID: 79159.

[23] Kaçar, F. and Ozcelep, Y. (2011) CDBA Based Voltage-Mode First-Order All-Pass Filter Topologies. IU-JEEE, 11, 1327-1332.

[24] Kilinc, S. and Cam, U. (2004) Realization of Allpass Filters Using Operational Transresistance Amplifier (OTRA). Proceeding of the IEEE 12th Signal Processing and Communications Applications Conference, 1, 133-136. http://dx.doi.org/10.1109/SIU.2004.1338276

[25] Kilinc, S. and Cam, U. (2004) Operational Transresistance Amplifier Based First-Order All-Pass Filter with an Application Example. Proceeding of the MWSCAS’ 04, 1, 65-68. http://dx.doi.org/10.1109/mwscas.2004.1353898

[26] Cakir, C., Cam, U. and Cicekoglu, O. (2005) Novel Allpass Filter Configuration Employing Single OTRA. IEEE Transactions on Circuits and Systems-II, 52, 122-125. http://dx.doi.org/10.1109/TCSII.2004.842055

[27] Tanaphatsiri, C., Jaikla, W. and Siripruchyanun, M. (2008) An Electronically Controllable Voltage-Mode First-Order All-Pass Filter Using Only Single CCCDTA. International Symposium on Communications and Information Technologies (ISCIT2008), Vientiane, 21-23 October 2008, 305-309. http://dx.doi.org/10.1109/iscit.2008.4700203

[28] Herencsar, N., Koton, J., Jerabek, J., Vrba, K. and Cicekoglu, O. (2011) Voltage-Mode All-Pass Filters Using Universal Voltage Conveyor and MOSFET-Based Electronic Resistors. Radioengineering, 20, 10-18.

[29] Biolek, D., Biolkova, V. and Kolka, Z. (2010) All-Pass Filter Employing Fully Balanced Voltage Differencing Buffered Amplifier. Proceedings of the IEEE Latin American Symposium on Circuits and Systems (LASCAS 2010), Iguacu Falls, 24-26 February 2010, 232-235. http://user.unob.cz/biolek/veda/articles/LASCAS2010 1.pdf

[30] Biolek, D., Senani, R., Biolkova, V. and Kolka, Z. (2008) Active Elements for Analog Signal Processing; Classification, Review and New Proposals. Radioengineering, 17, 15-32.

[31] Prasad, D., Bhaskar, D.R. and Singh, A.K. (2009) Multifunction Biquad Using Single Current Differencing Transconductance Amplifier. Analog Integrated Circuits and Signal Processing, 61, 309-313. http://dx.doi.org/10.1007/s10470-009-9310-1

[32] Frey, D.R. (1993) Log-Domain Filtering: An Approach to Current-Mode Filtering. IEE Proceedings G Circuits, Devices and Systems, 140, 406-416. 